\title{
UTILIZAÇÃO DE AMIRÉIAS (PRODUTO DA EXTRUSÃO AMIDO + URÉIA) COM DIFERENTES PROPORÇÕES DE URÉIA: 1. CONSUMO E DIGESTIBILIDADE APARENTE DA MATÉRIA SECA, FIBRA EM DETERGENTE NEUTRO E FIBRA EM DETERGENTE ÁCIDO ${ }^{1}$
}

\author{
Utilization of starea (product of starch + urea extrusion) with different urea \\ proportions: 1. Consumption and apparent digestibility of dry matter, \\ neutral detergent fiber and acid detergent fiber
}

\author{
Flávio Moreno Salvador², Júlio César Teixeira ${ }^{3}$, Juan Ramón Olalquiaga Perez ${ }^{3}$, \\ Antônio Ricardo Evangelista ${ }^{3}$, Joel Augusto Muniz ${ }^{4}$
}

\begin{abstract}
RESUMO
Este experimento foi realizado para avaliar amiréias com diferentes proporções de amido:uréia em suas composições, com o objetivo de verificar suas influências sobre o consumo e digestibilidade da MS, MO, FDN e FDA em ovinos alimentados exclusivamente com feno de coastcross. Foram utilizadas 16 ovelhas em um ensaio de digestibilidade in vivo, aleatoriamente distribuídas em quatro tratamentos constituídos por amiréias com 100, 150, 180 e 200\% de equivalente protéico, que se constituíram em suplementos protéicos administrados de forma isonitrogenada. Os consumos dos nutrientes considerados foram, (i) para MS, 834,15; 813,06; 907,96 e 804,62 g/dia; (ii) para FDN, 675,46; 654,13; 732,52 e 646,58 g/dia; (iii) para FDA, 328,42; 319,$23 ; 358,33$ e $315,29 \mathrm{~g} /$ dia, respectivamente, para as amiréias com 100, 150, 180 e $200 \%$ de equivalente protéico. As digestibilidades verificadas foram, (i) para MS, 53,64; 53,53; 54,26 e 55,03\%; (ii) para FDN, 58,93; 58,98; 59,74 e 59,63\%; e (iii) para a FDA, 54,42; 48,71; 49,76 e 54,90\%, respectivamente, para as mesmas amiréias mencionadas. Os resultados não foram afetados pelas diferentes amiréias e os valores observados encontram-se dentro de padrões normais para a espécie e o alimento (feno) utilizados no estudo. Pelos resultados, infere-se que as diferentes amiréias estudadas possuem a mesma eficiência quanto a propiciar liberação gradual de amônia no rúmen.
\end{abstract}

Termos para indexação: Feno de coastcross, fontes de nitrogênio, nitrogênio não-protéico, suplementação protéica.

\section{ABSTRACT}

An experiment was conducted to evaluate starea at different starch:urea proportions in their compositions with the purpose of verifing their influences on the consumption and digestibility of DM, OM, NDF and ADF in sheep fed singly on coastcross hay. Sixteen ewes were utilized in an in vivo digestibility trial, distributed randomly into four treatments made up of starea with 100,150, 180 and $200 \%$ of protein equivalent which became protein supplements fed in an isonitrogen form. The consumption and digestibilities of the nutrients in issue were not affected (P.0,05) by the different starea and the values observed were within normal patterns for both the species and feed (hay) utilized in the study. The results suggest that the different starea studied posses the same efficiency as to providing gradual release of ammonia in the rumen.

Index terms: Coastcross hay, nitrogen sources, non-protein nitrogen, protein supplementation.

(Recebido para publicação em 14 de abril de 2003 e aprovado em 8 de setembro de 2003)

\section{INTRODUÇÃO}

A capacidade dos animais de consumir alimentos em quantidades suficientes para alcançar seus requerimentos de mantença e produção é um dos fatores mais importantes em sistemas de produção, em grande parte dependentes de volumosos. O consumo de alimentos é influenciado por vários fatores e, quando a densidade energética desses é mais baixa, como é o caso de dietas à base de volumosos, o consumo poderá ser limitado pelo efeito do enchimento (MERTENS, 1994).

\footnotetext{
1. Parte da dissertação de mestrado em Zootecnia do primeiro autor, apresentada a Universidade Federal de Lavras/UFLA - Caixa Postal 37 - 37200 000 - Lavras, MG.

2. Zootecnista, aluno de doutorado em Zootecnia da UFLA, moreno.flavio@ig.com.br

3. Professor Titular do Departamento de Zootecnia da UFLA.

4. Professor Titular do Departamento de Ciências Exatas da UFLA.
} 
A fibra em detergente neutro (FDN) é uma medida do conteúdo total de fibra insolúvel do alimento e constitui o parâmetro mais usado para o balanceamento de dietas, uma vez que tem sido utilizada como fator interferidor da qualidade da mesma e não são poucos os estudos que relacionam a quantidade de FDN nos alimentos e o respectivo consumo desses em ruminantes (SOEST, 1994).

Entre as características da dieta que regulam a ingestão e a digestibilidade das fibras, salienta-se a deficiência no conteúdo ruminal de compostos nitrogenados. Quando o suprimento de nitrogênio $(\mathrm{N})$ não atende aos requerimentos dos microrganismos ruminais, ocorre limitação do crescimento microbiano e depressão da digestão da parede celular, resultando em diminuição do consumo (WILSON e KENNEDY, 1996).

A proteína é um dos nutrientes de custo mais elevado na dieta dos animais e a economia da produção é altamente dependente da eficiência da utilização desse nutriente. Por isso, compostos nitrogenados nãoprotéicos (NNP) têm sido utilizados na suplementação de animais ruminantes, representando uma alternativa para atender às exigências em proteína, ao mesmo tempo em que reduz o custo desse nutriente (LOPEZ, 1984).

A eficiência de utilização do $\mathrm{N}$ proveniente de compostos nitrogenados não-protéicos (como a uréia) pelos microrganismos do rúmen depende de uma série de fatores, entre eles a perfeita sincronização entre liberação de amônia decorrente da hidrólise da uréia e da presença de energia para síntese de proteína microbiana (CAMERON, 1991). A hidrólise da uréia é extremamente rápida, o que pode facultar a perda de $\mathrm{N}$ pela urina, e nos últimos anos, tem havido um interesse considerável na redução das perdas de $\mathrm{N}$ pelos ruminantes (SANTOS, 1998).

A sincronização entre a liberação de amônia no rúmen e a oferta de esqueletos de carbono, advinda da degradação de carboidratos, poderia tornar a síntese de proteína microbiana, bem como a degradação das fibras alimentares, mais eficientes (SMITH, 1979). Nesse propósito, a amiréia, produto resultante da extrusão de fonte de amido com uréia, parece ser eficiente, visto que o processamento desses componentes (amido e uréia) pode ser benéfico em dois sentidos: (1) aumentando a velocidade de fermentação do amido no rúmen, e (2) reduzindo a intensidade de liberação de amônia oriunda da uréia, compatibilizando os dois fatores para a síntese de proteína microbiana (HELMER, 1970; BARTLEY e DEYOE, 1975).

Uma vez que a uréia tem como grande vantagem, em relação às outras fontes de $\mathrm{N}$, o seu menor custo por unidade de $\mathrm{N}$, amiréias que contenham maiores proporções de uréia, sem que percam seus principais atributos (liberação mais cadenciada de $\mathrm{N}$, com conseqüente redução nas perdas deste nutriente), podem ser importantes e econômicas fontes de NNP para alimentação de ruminantes.

Assim, conduziu-se o presente trabalho com o objetivo de avaliar amiréias com diferentes proporções amido:uréia suplementando dietas de ovinos alimentados exclusivamente com volumoso (feno de coastcross).

\section{MATERIAL E MÉTODOS}

O experimento foi realizado nas instalações do Laboratório Animal do Departamento de Zootecnia da UFLA, em Lavras-MG, em dois períodos subseqüentes (janeiro e fevereiro de 2002). Foram utilizadas dezesseis ovelhas adultas, com predomínio da raça Morada Nova, com peso médio e desvio padrão inicial de 46,36 $\pm 4,71 \mathrm{~kg}$ que, depois de vermifugadas, foram instaladas aleatoriamente em gaiolas metabólicas individuais, adequadas para ensaios de digestibilidade in vivo, providas de comedouro, bebedouro e cocho próprio para suplemento mineral. Cada gaiola metabólica possuía, acoplado ao assoalho, um sistema de captação de fezes e urina. As fezes eram recolhidas em bandejas plásticas e a urina ficava acondicionada em baldes plásticos, adaptados com uma tela separadora, evitando que as fezes e a urina se misturassem. Cada balde recebeu 100 $\mathrm{mL}$ de solução de $\mathrm{HCl}$ a $10 \%$ a fim de evitar perda de $\mathrm{N}$ para o ambiente.

A alimentação dos animais consistiu de feno de capim coastcross (Cynodon dactylon L. Pers.), moído em partículas de $1 \mathrm{~cm}$ e oferecido em duas refeições diárias (às 7 horas e às 17 horas), sendo cada refeição constituída de $50 \%$ do total diário ofertado. A quantidade diária de feno oferecido para cada animal foi próxima a $2 \%$ do peso vivo, alcançando por volta de 1.000 $\mathrm{g}$ de feno.dia ${ }^{-1}$ (base matéria natural).

Cada animal tinha à disposição água limpa e fresca, à vontade, trocada diariamente, e contavam também suplemento mineral completo (macro e microminerais já misturados com cloreto de sódio), sempre disponível. 
Os tratamentos consistiram de quatro amiréias, produzidas com milho moído como fonte de amido, cada uma delas com uma concentração diferente de uréia e, conseqüentemente, com um equivalente protéico (EqPB) próprio, a saber: AM100, AM150, AM180 e AM200, com aproximadamente 100, 150, 180 e 200\% de EqPB, respectivamente. Cada animal (parcela experimental) recebeu, em cada um dos dois períodos experimentais, apenas uma entre as quatro amiréias supra como fonte de proteína bruta (PB) suplementar.

As composições químicas do feno e dos suplementos (amiréias), segundo análises realizadas no laboratório de nutrição animal da UFLA, encontramse apresentadas na Tabela 1.

A quantidade diária de PB suplementada via amiréia correspondeu a $3 \%$ do alimento fornecido (próximo a $30 \mathrm{~g}$ de $\mathrm{PB}$ ), convertida na quantidade de amiréia pertinente a cada parcela (animal), segundo o tratamento que lhe fosse atribuído e essa foi administrada homogeneizada ao feno, de forma parcelada, sendo $50 \%$ da quantidade total diária em cada uma das duas refeições.

Os dois períodos experimentais foram consecutivamente imediatos, um após o outro, e apresentaram, cada um, uma fase pré-experimental e uma fase de coletas.

Nas fases de coleta, o feno ofertado e as amiréias foram amostrados em dias alternados; essas amostras foram posteriormente homogeneizadas, formando uma única amostra composta (para cada tipo de alimento) e o alimento recusado (sobras) era pesado e amostrado diariamente. As fezes, bem como a urina, eram recolhidas pela manhã, após o manejo alimentar, sendo pesadas (fezes) ou tinham seus volumes medidos (urina) e eram então amostradas e congeladas para análises posteriores.

Amostras de amiréia foram analisadas para matéria seca (MS) e PB; as amostras de feno, sobras de alimentos e fezes o foram para (MS), matéria orgânica (MO) e PB, segundo as metodologias descri- tas por Silva (1990) e utilizaram os métodos descritos por Soest et al., (1991) para a determinação da FDN e da fibra em detergente ácido (FDA) do feno, das sobras e das fezes. O delineamento experimental utilizado foi o inteiramente casualizado, com quatro tratamentos e quatro repetições por tratamento, compostas cada uma por um único animal e o experimento foi repetido em seus dois períodos, para o estudo do consumo e digestibilidade aparente da MS, MO, FDN e FDA, resultando em um total de 32 parcelas experimentais. A análise estatística dos dados foi realizada utilizando-se o procedimento "GLM" do software Statistical Analysis System (SAS INSTITUTE, 1991), conforme o modelo estatístico de análise conjunta:

$$
\mathbf{Y}_{\mathrm{ijk}}=\mu+\mathbf{T}_{\mathrm{i}}+\mathbf{P}_{\mathbf{j}}+\mathbf{T} \mathbf{P}_{\mathrm{ij}}+\mathbf{e}_{\mathrm{ijk}},
$$

em que:

$\mathbf{Y}_{\mathbf{i j k}}$ representa o valor observado $\mathbf{k}$ do experimento $\mathbf{i}$ no tratamento $\mathbf{j}$;

$\mu$ é uma constante associada a todas as observações;

$\mathbf{T}_{\mathbf{i}}$ é o efeito do tratamento $\mathbf{i}, \operatorname{com} \mathbf{i}=1,2,3$ e 4;

$\mathbf{P}_{\mathbf{j}}$ é o efeito do período $\mathbf{j}, \operatorname{com} \mathbf{j}=1$ e 2 ;

$\mathbf{T P}_{\mathrm{ij}}$ é efeito da interação entre o tratamento i e o período j; e

$\mathbf{e}_{\mathbf{i j k}}$ é o erro experimental associado a $\mathbf{Y}_{\mathbf{i j k}}$, com $\mathbf{k}=$ 1,2,3 e 4; e que, por hipótese, tem distribuição normal com média zero e variância $\ddot{a ̆}^{2}$.

Em caso de diferença significativa entre os tratamentos, as médias entre esses foram analisadas pelo teste de Tukey ao nível de 5\% de probabilidade.

\section{RESULTADOS E DISCUSSÃO}

Na Tabela 2 são apresentados os dados de consumo da MS, MO, FDN e FDA, expressos em g.dia ${ }^{-1}$, porcentagem do peso vivo (\% PV) e g. $\mathrm{kg}^{-1} \mathrm{PV}$ metabólico, e os respectivos coeficientes de digestibilidade.

TABELA 1 - Composição química do feno e das amiréias utilizadas (em \%MS).

\begin{tabular}{lcccccc}
\hline \multicolumn{1}{c}{ Ingredientes } & MS & PB & MO & FDN & FDA & CHOT $^{\mathbf{1}}$ \\
\hline Feno de coastcross & 87,44 & 10,24 & 94,36 & 81,25 & 40,03 & 82,53 \\
Amiréia 100 & 91,52 & 117,87 & - & - & - & - \\
Amiréia 150 & 94,62 & 139,00 & - & - & - & - \\
Amiréia 180 & 90,36 & 177,82 & - & - & - & - \\
Amiréia 200 & 91,42 & 214,76 & - & - & - & - \\
\hline
\end{tabular}

(1)Carboidratos totais, calculados pela equação: CHOT = \%MO - \%PB - \%EE 
TABELA 2 - Consumos médios de MS, MO, FDN e FDA e respectivos coeficientes de digestibilidades aparente.

\begin{tabular}{|c|c|c|c|c|c|}
\hline \multirow{2}{*}{ Variáveis } & \multicolumn{4}{|c|}{ Tratamentos (Amiréias) } & \multirow{2}{*}{$\operatorname{CV}(\%)$} \\
\hline & AM100 & AM150 & AM180 & AM200 & \\
\hline \multicolumn{6}{|c|}{ Consumo de MS } \\
\hline g/dia & 834,15 & 813,06 & 907,96 & 804,62 & 14,50 \\
\hline$\%$ Peso vivo & 1,90 & 1,81 & 2,06 & 1,82 & 13,46 \\
\hline g MS/kg PV ${ }^{0,75}$ & 48,83 & 46,80 & 53,07 & 46,93 & 12,92 \\
\hline \multicolumn{6}{|c|}{ Consumo de MO } \\
\hline $\mathrm{g} / \mathrm{dia}$ & 787,32 & 767,40 & 856,98 & 759,44 & 14,50 \\
\hline$\%$ Peso vivo & 1,79 & 1,71 & 1,95 & 1,75 & 13,40 \\
\hline g MS/kg PV ${ }^{0,75}$ & 46,09 & 44,17 & 50,09 & 44,30 & 12,93 \\
\hline \multicolumn{6}{|c|}{ Consumo de FDN } \\
\hline $\mathrm{g} / \mathrm{dia}$ & 675,46 & 654,13 & 732,52 & 646,58 & 15,25 \\
\hline \% Peso vivo & 1,54 & 1,46 & 1,66 & 1,46 & 14,34 \\
\hline $\mathrm{g} \mathrm{MS} / \mathrm{kg} \mathrm{PV}^{0,75}$ & 39,55 & 37,64 & 42,83 & 37,70 & 13,87 \\
\hline \multicolumn{6}{|c|}{ Consumo de FDA } \\
\hline g/dia & 328,42 & 319,23 & 358,33 & 315,29 & 15,98 \\
\hline$\%$ Peso vivo & 0,75 & 0,71 & 0,81 & 0,71 & 15,41 \\
\hline $\mathrm{g} \mathrm{MS} / \mathrm{kg} \mathrm{PV}^{0,75}$ & 19,24 & 18,36 & 20,96 & 18,39 & 14,84 \\
\hline \multicolumn{6}{|c|}{ Coeficientes de Digestibilidade (\%) } \\
\hline CDMS & 53,64 & 53,53 & 54,26 & 55,03 & 5,32 \\
\hline CDMO & 54,77 & 54,29 & 54,90 & 55,97 & 5,13 \\
\hline CDFDN & 58,93 & 58,98 & 59,74 & 59,63 & 5,56 \\
\hline CDFDA & 54,42 & 48,71 & 49,76 & 54,90 & 11,62 \\
\hline
\end{tabular}

Embora os resultados de consumo obtidos com os animais que receberam o tratamento AM180 tenham sido numericamente superiores aos demais, não houve efeito de tratamentos sobre os consumos de MS, MO, FDN e FDA, em nenhuma das formas de expressá-los.

Os valores de ingestão total $\left(\mathrm{g} \cdot \mathrm{dia}^{-1}\right)$ encontrados são inferiores aos preconizados pelo NRC (1985) para ovelhas em manutenção com peso vivo médio um pouco superior ao dos animais utilizados neste trabalho (50 $\mathrm{kg}$ vs 46,36 kg); em relação à ingestão mensurada em $\%$ do peso vivo, os animais deste ensaio alcançaram consumos menores do que os verificados por Rodrigues (1998), que trabalharam com carneiros adultos castrados e feno de coastcross e verificaram $2,1 \%$ PV de consumo contra 1,9\% encontrado nesta pesquisa.

Martin (1981) ressaltam que forragens de baixa qualidade (menos que $7 \%$ de proteína bruta) têm suas ingestões limitadas por aportes insuficientes de nitrogênio, o que limitaria o crescimento microbiano com conseqüente depressão da digestão da parede celular, resultando em diminuição do consumo (WILSON e KENNEDY, 1996). No entanto, essa não parece ter sido 
a circunstância do presente estudo, visto que a concentração protéica do feno de coastcross utilizado foi maior que $10 \%$; considerando os consumos das amiréias, a dieta ingerida pelos animais apresentou concentração protéica superior a $13 \%$.

Situação similar se deu nos trabalhos de Seixas (1996) e de Salman (1997), ambos também com ovinos (cordeiros), em que se compararam o farelo de algodão, a uréia e a amiréia $(38,8 \%$ EqPB) como fontes protéicas suplementares. As dietas também apresentavam por volta de $13 \%$ PB e as ingestões diárias de MS não diferiram entre si, apesar de numericamente serem maiores e um pouco mais heterogêneas entre si do que as encontradas neste trabalho $\left(71,4 ; 64,1\right.$ e $68,8 \mathrm{~g} \cdot \mathrm{kg}^{-1} \mathrm{PV}^{0,75} \mathrm{pa}$ ra o farelo, a uréia e a amiréia, respectivamente). Essa ocorrência parece vir de encontro à afirmação de Ørskov (1992), segundo o qual o nitrogênio suplementar pode não influir no consumo de matéria seca quando a dieta apresenta teores de proteína superiores a $12 \%$, também relatado por Siddons (1985), que trabalhando com níveis crescentes de $\mathrm{N}$ dietético (que não foi o caso do presente ensaio), não observaram diferenças entre ingestões de MS em ovinos.

Os coeficientes de digestibilidade aparente, tanto da matéria seca (CDMS) como da matéria orgânica (CDMO), bem como o consumo das porções digestíveis dessas frações, também podem ser visualizados na Tabela 2 e não foram constatadas diferenças significativas entre os tratamentos. Os coeficientes de digestibilidade aparente da MS (CDMS) alcançados no presente estudo foram inferiores aos verificados nos animais suplementados com amiréia no ensaio de Salman (1997) (CDMS $=67,7 \%$ ); no entanto, pode-se atribuir a superioridade obtida naquele estudo ao fato de a dieta utilizada por aqueles autores conter concentrado em alta proporção. Em circunstância em que a dieta era basicamente constituída apenas por volumoso, Silva (1994), utilizando amiréia com $48 \%$ EqPB, obtive 52 e $57 \%$ como coeficientes de digestibilidade da MS e da MO (CDMS e CDMO), respectivamente, para a palha de arroz como único alimento administrado a ovinos.

Os consumos de FDN verificados (média geral de 677,17 g.animal ${ }^{-1}$.dia ${ }^{-1}$ ) foram ligeiramente superiores aos obtidos por Moreira (2001), em ovinos que receberam o feno de coastcross como alimento exclusivo $\left(666,57\right.$ g.animal ${ }^{-1} \cdot$ dia $\left.^{-1}\right)$. Embora o presente estudo não tenha objetivado avaliar 'níveis' protéicos, mas sim a eficiência da extrusão de amido e uréia em amiréias elaboradas com diferentes níveis de inclusão da uréia, é interessante verificar que alguns autores, estudando os efeitos de níveis de energia e proteína na dieta de ovelhas, não observaram efeito do nível de proteína (VALADARES, 1997), bem como também não encontraram efeito do tipo de proteína, de alta ou baixa degradabilidade ruminal (GUIDI, 1999; SILVA, 2002) sobre a ingestão de FDN.

As diferentes amiréias utilizadas não afetaram a digestibilidade aparente da FDN (CDFDN). A CDFDN média foi de 59,3\%, sendo superior à obtida por Ezequiel (2001), quando compararam a uréia à amiréia (38,8\% EqPB), em dietas isoprotéicas, como fonte suplementar de N. Esses autores obtiveram superioridade do tratamento com amiréia sobre o tratamento uréia em cerca de $40 \%$, no tocante à digestibilidade da FDN. Importante mencionar que quando ovinos tiveram o feno de coastcross como alimento único, não recebendo nenhum tipo de suplementação nitrogenada (MOREIRA, 2001), as digestibilidades da FDN alcançadas foram $16,5 \%$ inferiores às obtidas no presente experimento. Deve ser ressaltado ainda que os coeficientes de digestibilidade aparente da FDN obtidos, todos próximos a $60 \%$, não são comuns na literatura em estudos com ovinos (LAVEZZO et al., 1996), bem como com bovinos (DUTRA et al., 1997) quando a dieta é composta com mais de $85 \%$ de volumoso.

Diante desse aspecto, uma possibilidade a considerar é o fato de que todos os tratamentos tenham permitido eficiente degradabilidade da FDN da dieta.

Semelhantemente ao ocorrido com as variáveis anteriores, não houve influência do tipo de amiréia utilizada na suplementação dos animais sobre a ingestão da FDA, independentemente do modo de mensurá-la, nem sobre a digestibilidade aparente desse nutriente (CDFDA). Os consumos expressos em base de gramas por unidade de tamanho metabólico $\left(\mathrm{g}^{\mathrm{kg}} \mathrm{kg}^{-1} \mathrm{PV}^{0,75}\right.$ ) são superiores aos verificados por Coutinho Filho (1995) quando avaliaram fontes protéicas suplementares para ovinos. No entanto, esses autores trabalharam com dietas em que havia inclusão de concentrado (40\%), com menores concentrações de FDA (31,6 e $24,8 \%$ de FDA para as dietas completas com farelo de algodão + línter e uréia, respectivamente, contra $40,03 \%$ presentes no feno utilizado no presente trabalho). Entretanto, quando as dietas, ainda que compostas de volumoso + concentrado, apresentaram teores de FDA similares aos do presente estudo (por volta de $40 \%$ ), verificaram consumos maiores (34 g. $\mathrm{kg}^{-1}$ $\mathrm{PV}^{0,75}$ ) do que os aqui encontrados (média de 19,24 g. $\mathrm{kg}^{-1} \mathrm{PV}^{0,75}$, ainda que, em termos de porcentagem do peso vivo (\%PV), os valores tivessem sido muito próximos (RESENDE, 1995). 
Bolzan (2002), ao estudarem a forma de administração de grãos de milho associado à uréia (inteiro, moído ou extrusado) para ovinos, não encontraram diferenças significativas quanto às digestibilidades da MS, FDN e FDA; no entanto, em termos numéricos, verificaram que o tratamento do milho e da uréia por extrusão permitiu melhoras no coeficiente de digestibilidade da FDA da ordem de 11 e $25 \%$, comparativamente à administração da uréia com grãos inteiros ou apenas moídos, respectivamente.

\section{CONCLUSÕES}

Em face da igualdade nas performances obtidas, relativas às variáveis avaliadas, pode-se sugerir que as proporções amido:uréia estudadas no preparo de amiréia tenham a mesma eficiência qualitativa quanto ao processo de extrusão, inferindo-se, assim, que amiréias com proporções mais elevadas de uréia (até $70 \%$ aproximadamente) poderiam constituir suplementos nitrogenados não-protéicos eficientes, permitindo alcançar maior economia na suplementação nitrogenada de ruminantes, sem perder as vantagens qualitativas de liberação gradativa de amônia no rúmen, já reconhecidas em amiréias com menores concentrações de uréia.

\section{REFERÊNCIAS BIBLIOGRÁFICAS}

BARTLEY, E. E.; DEYOE, C. W. Starea as a protein replace for ruminants. Feedstuffs, Minneapolis, v. 47, n. 30, p. 42-44, 1975.

BOLZAN, I. T. Consumo e digestibilidade aparente em ovinos alimentados com diferentes processamentos do grão de milho e três níveis de concentrado. In: REUNIÃO ANUAL DA SOCIEDADE BRASILEIRA DE ZOOTECNIA, 39., 2002, Recife. Anais... Recife: SBZ, 2002. CD-ROM.

CAMERON, M. R. Effects of urea and starch on rumen fermentation, nutrient passage to the duodenum and performance of cows. Journal of Dairy Science, Champaign, v. 74, n. 4, p. 1321-1336, Apr. 1991.

COUTINHO FILHO, J. L. V. Efeito de fontes de nitrogênio sobre a ingestão e digestibilidade aparente de diferentes rações. Revista da Sociedade Brasileira de Zootecnia, Viçosa, v. 24, n. 6, p. 1038-1044, jun. 1995.
DUTRA, A. R. Efeitos dos níveis de fibra e das fontes de proteínas sobre o consumo e digestão dos nutrientes em novilhos. Revista Brasileira de Zootecnia, Viçosa, v. 26, n. 4, p. 787-796, abr. 1997.

EZEQUIEL, J. M. B. Digestibilidade aparente da energia e da fibra de dietas para ovinos contendo uréia, amiréia ou farelo de algodão. Revista Brasileira de Zootecnia, Viçosa, v. 30, n. 1, p. 231-235, jan. 2001.

GUIDI, M. T. Efeito de teores e fontes de proteína sobre o desempenho de vacas de leite e digestibilidade dos nutrientes. 1999. 92 f. Dissertação (Mestrado em Agronomia ) - Escola Superior de Agricultura "Luiz de Queiroz", Piracicaba , 1999.

HELMER, L. G. Feed processing. V: effect of an expansion processed mixture of grain and urea (Starea) on nitrogen utilization in vitro. Journal of Dairy Science, Champaign, v. 53, n. 3, p.330-335, Mar. 1970.

LAVEZZO, O. E. N. M.; LAVEZZO, W.; BURINI, R. C. Efeitos nutricionais da substituição parcial do farelo de soja por uréia, em dietas de ovinos: comparação da digestibilidade aparente e balanço de nitrogênio com a cinética do metabolismo da ${ }^{15} \mathrm{~N}$-glicina. Revista da Sociedade Brasileira de Zootecnia, Viçosa, v. 25, n. 2, p. 282-297, fev. 1996.

LOPEZ, J. Uréia em rações para produção de leite. In: SIMPÓSIO SOBRE NUTRIÇÃO DE BOVINOS, 2., 1984, Piracicaba. Anais... Piracicaba: FEALQ, 1984. p. 200-225.

MARTIN, L. C. Effect of level and form of supplemental energy and nitrogen on utilization of low quality roughages by sheep. Journal of Animal Science, Champaign, v. 53, n. 2, p. 479-488, Feb. 1981.

MERTENS D. R. Regulation of forage intake. In: FAHEY JÚNIOR, G. C. (Ed.). Forage quality, evaluation and utilization. Madison: American Society of Agronomy, 1994. p. 450-493.

MOREIRA, A. L. Consumo e digestibilidade aparente dos nutrientes da silagem de milho e dos fenos de alfafa e de capim coastcross, em ovinos. Revista Brasileira de Zootecnia, Viçosa, v. 30, n. 3, p. 1099-1105, mar. 2001. 
NATIONAL RESEARCH COUNCIL. Nutrient requirements of sheep. 6. ed. Washington: National Academy, 1985. 99 p.

ØRSKOV, E. R. Protein nutrition in ruminants. 2. ed. London: Academic, 1992. 175 p.

RESENDE, F. D. de. Fibra em detergente neutro versus fibra em detergente ácido na formulação de dietas para ruminantes. Revista da Sociedade Brasileira de Zootecnia, Viçosa, v. 24, n. 3, p. 342-350, mar. 1995.

RODRIGUES, P. H. M. Digestibilidade aparente com ovinos de duas gramíneas do gênero Cynodon [Cynodon dactylon (L.) Pers]. In: REUNIÃO ANUAL DA SOCIEDADE BRASILEIRA DE ZOOTENCIA, 35., 1998, Botucatu. Anais... Botucatu: SBZ, 1998. p. 503.

SALMAN, A. K. D. Estudo do balanço nitrogenado e da digestibilidade da matéria seca e proteína de rações, para ovinos, suplementadas com amiréia, uréia ou farelo de algodão. Revista Brasileira de Zootecnia, Viçosa, v. 26, n. 1, p. 179-185, jan. 1997.

SANTOS, F. A. P. Effects of undegradable protein on dairy cow performance: a 12-year literature review. Journal of Dairy Science, Champaign, v. 81, n. 9, p. 3182-3213, Sept. 1998.

SAS INSTITUTE. SAS user's guide: statistics. 5. ed. Cary, 1991. 1290 p.

SEIXAS, J. R. C. Desempenho de bovinos confinados e digestibilidade aparente com ovinos recebendo amiréia, uréia ou farelo de algodão. 1996. 73 f. Dissertação (Mestrado em Zootecnia) - Universidade Estadual de São Paulo, Jaboticabal, 1996.

SIDDONS, R. C. Nitrogen digestion and metabolism in sheep consuming diets containing contrasting forms and leves of N. British Journal of Nutrition, Cambridge, v. 54, n. 1, p.175-187, Jan. 1985.
SILVA, D. J. Análise de alimentos: métodos químicos e biológicos. Viçosa: UFV, 1990. 196 p.

SILVA, J. F. Valor nutritivo da palha de arroz suplementada com amiréia, fubá+uréia e farelo de soja. Pesquisa Agropecuária Brasileira, Brasília, v. 29, n. 9, p. 1475-1481, set. 1994.

SILVA, L. das D. F. Digestão total e parcial de alguns componentes de dietas contendo diferentes níveis de casca de soja e fontes de nitrogênio, em bovinos. Revista Brasileira de Zootecnia, Viçosa, v. 31, n. 3, p. 1258-1268, mar. 2002.

SMITH, R. H. Synthesis of microbial nitrogen compounds in the rumen and their subsequent digestion. Journal of Animal Science, Champaign, v. 49, n. 6 p. 1604-1614, June 1979.

SOEST, P. J. van. Nutritional ecology of the ruminant. 2. ed. Ithaca: Cornell University, 1994. 476 p.

SOEST, P. J. van; ROBERTSON, J. B.; LEWIS, B. A. Methods for dietary fiber, neutral detergent fiber and non starch polysaccharides in relation to animal nutrition. Journal of Animal Science, Champaign, v. 71, n. 10, p. 3583-3597, Oct. 1991.

VALADARES, R. D. F. Níveis de proteína em dietas de bovinos. 1: consumo e digestibilidades aparentes totais e parciais. Revista Brasileira de Zootecnia, Viçosa, v. 26, n. 6, p. 1252-1258, jun. 1997.

WILSON, J. R.; KENNEDY, P. M. Plant and animal constraints to voluntary feed intake associated with fiber characteristics and particle breakdown and passage in ruminants. Australina Journal of Agricultural Research, Victoria, v. 47, n. 1, p. 199-225, Jan. 1996. 